\title{
The Gathering "Perfect Storm"
}

\section{It is Up to Us to Make History}

After I gave a talk here at Los Alamos last August on "Our Obligations toward the Scientific Community," I received an e-mail from a postdoc: "Interesting, frightening, and inspiring..." My talks have been called many things, but never "frightening" before - at least not to my face.

I spoke about the global flow of four factors: energy, carbon, talent, and money. The trends in each are robust, and they predict the confluence of gigantic changes in the next 50 years that could produce a frightening "Perfect Storm" in the human landscape.

In this first letter of my presidency of the Materials Research Society, I will outline the compelling opportunity and unique obligations we as materials researchers have to help mitigate the storm damage. The 2005 National Academies report "Rising above the Gathering Storm" (www.nap.edu/catalog/11463.html) gave rise to the opportunity, and we are obligated to rise to its challenge.

Energy and carbon flow are challenging global issues. Carbon-neutral energy is a must. Just as 20th-century materials research underpins current energy technologies, 21st-century materials research will underpin future energy technologies.

Thus, the materials community has a special role in the "Perfect Storm," and the stakes are high. If our seas rise, the displacement of populations could be biblical.

Talent and money flow are national

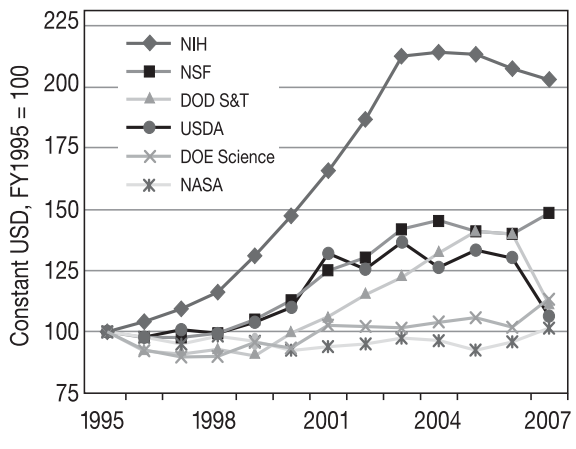

Figure 1. Funding trends in federal research and development for selected agencies in FY 1995-2007. Source: American Association for the Advancement of Science analyses of research and development in AAAS Reports VIII-XXXI. FY 2007 figures are President's request. R\&D includes conduct of $R \& D$ and $R \& D$ facilities. March 2006 revised (C) 2006 AAAS.

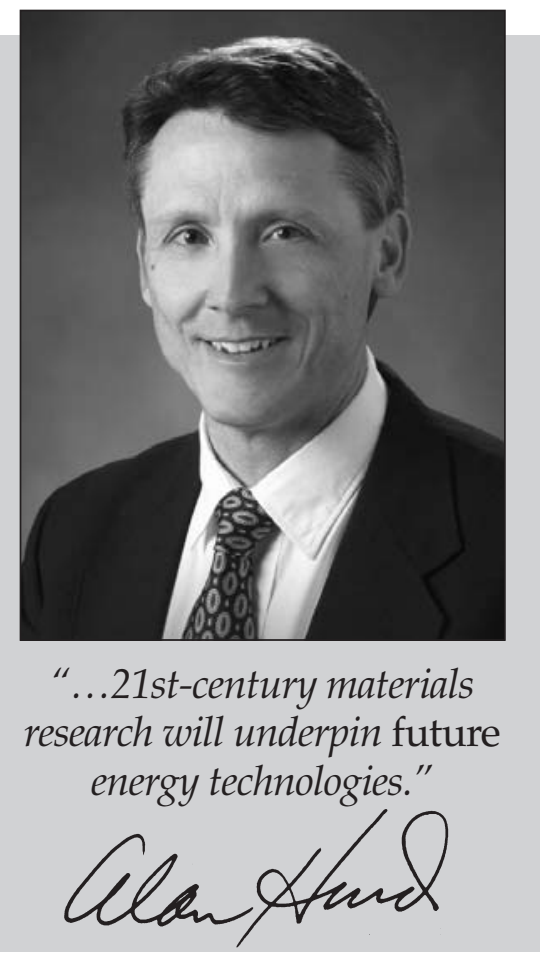

issues, but nations are necessarily linked. Because it may take several Nobel Prizes to solve the problem of creating carbonneutral energy, we need the full engagement of the world's talent. Poverty enormously depletes the talent pool, as does discrimination against women and minorities in many regions. Even the United States, which has the resources and the obligation to make the largest contribution, falls short of potential because its talent is flowing away from science and engineering. Our species has put itself in a fix.

Greater investment in physical sciences is a necessary first step. Under proposed legislation in the United States, funding would double over five to seven years in key agencies for relatively little cost-less than research "earmarks" (pork) alone! This first step won't happen or be sustained without our advocacy.

The opportunity to double research funding is rare in the United States, Europe, and Asia but not unprecedented. U.S. funding for biosciences doubled over the last decade (Figure 1), leading to substantial advances. Physical sciences lag. The proposed legislation has unprecedented bipartisan support; there are similar hopeful developments under the Seventh Framework Programme in Europe.
Indeed, science policies in Washington, Brussels, and Beijing are linked.

We are approaching a singularity in opportunity, and we cannot ignore it.

I have challenged the Society to double its advocacy efforts in support of funding increases and to challenge sister societies to do the same. MRS spends an average of $\$ 16$ (from all income sources) per member on advocacy, compared with \$24 per member for the American Physical Society. Every MRS member, including non-U.S. members, can participate.

Sustained advocacy is needed if funding is to double. The mean lifetime for U.S. initiatives is only three years, and the unrealized doubling of the National Science Foundation budget (2002-2007) shows what can happen without long-term support. Through the International Union of Materials Research Societies (IUMRS), our effort will link outside the United States.

Back to the postdoc. She wrote, "I am sincerely interested in helping to reduce the impact of the impending global energy crisis. I am not sure how to begin. Some of the problems involving energy can be addressed through materials science and engineering. I would truly appreciate any suggestions and advice you could provide on how I, as an aspiring materials scientist, could make a difference."

This request for advice struck me profoundly. I replied weakly, "Your obligation, in my opinion, is to look for research opportunities and to get involved in advocacy," and I promised a more complete answer later. Over the next 11 months, I will complete my response through these letters. Upcoming topics include international linkage in science policy, strengthening our collective voice through recruitment, "open access" in publications to enhance information exchange, the Society's stance on energy materials research, talent lost in underrepresented groups and to nontechnical fields, and the role of public outreach.

We must seize the day. We can change history.

The postdoc thanked me for my advice, writing, "I look forward to getting involved with advocacy in science, engineering, and technology. In the meantime, my husband and I plan to attack the growing energy problem in a more personal way by adding a solar heater to our home. Every little bit has to help."

AlAN J. HuRd 2007 MRS President 